\title{
Urethral candidosis in a male treated with amphotericin B instillation
}

\author{
J. D. J. PARKER \\ St Bartholomew's Hospital, London, E.C.1
}

\begin{abstract}
URETHRAL candidosis is uncommon in the male (Rohatiner, 1967) and there is some difference of opinion concerning the minimum criteria for such a diagnosis. In most reported cases the symptoms and signs are slight or even absent, commonly consisting of very slight urethral discharge with or without dysuria or urethral irritation. A urethral smear typically reveals mycelia and spores of $C$. albicans with few polymorphonuclear leucocytes and numerous epithelial cells. Harkness (1950) stressed the diagnostic importance of spores in repeated urethral smears. Catterall (1966) considered that the presence of both yeast forms and mycelia together in smears was essential for the diagnosis of candidal urethritis.
\end{abstract}

\section{Case report}

A man aged 32 years of Anglo-Italian parentage had been circumcised as an infant and in 1963 had contracted gonorrhoea for which he was treated with penicillin. He was first seen at St. Bartholomew's Hospital in the Spring of 1968 when he was given a course of tetracycline for non-gonococcal urethritis. He admitted sexual intercourse with a regular girl friend 3 days before attendance. When seen again 3 weeks later he continued to complain of a 'sticky' urethral discharge worse in the early morning. A urethral smear revealed moderate numbers of pus and epithelial cells together with pseudomycelia and spores typical of $C$. albicans; the diagnosis was subsequently confirmed by positive results to culture on Sabouraud's medium (Figs 1 and 2 ).

$\mathrm{He}$ was given a single injection of streptomycin $1 \mathrm{~g}$. intramuscularly and sulphadimidine tablets $5 \mathrm{~g}$. daily in divided doses for 5 days.

A week later he still had a slight mucoid discharge; smear and culture results were again positive for $C$. albicans, but the smear was now almost free from pus cells although epithelial cells were plentiful. Similar findings were observed a week later. A prostatic smear was negative for Candida and a mid-stream specimen of urine showed no evidence of fungi on microscopy or culture. Urethroscopy revealed no abnormality.

Received for publication July 29, 1969.

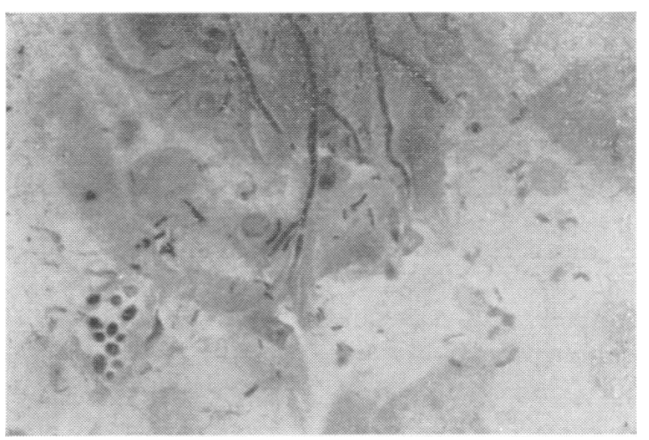

FIG. 1 Smear taken from urethra, showing mycelia and spores of $\mathrm{C}$. albicans

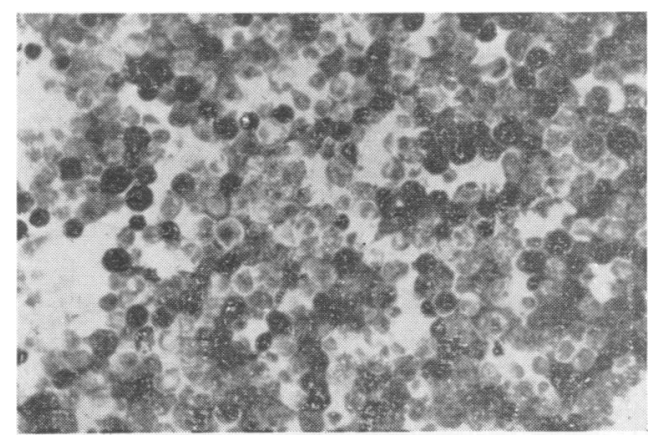

FIG. 2 Culture from urethra on Sabouraud's medium, showing vegetative forms of $\mathrm{C}$. albicans

It was decided to treat the patient by urethral instillation with amphotericin B ('Fungizone' Squibb); $25 \mathrm{mg}$. of the powder were dissolved in $5 \mathrm{ml}$. sterile water and $2.5 \mathrm{ml}$. 5 per cent. dextrose solution, and this fluid was syringed into the urethra and left in situ for 15 minutes, the meatus being occluded by a penile clamp. Three 'early morning' urethral smears and Sabouraud cultures carried out during the next 4 weeks showed no evidence of Candida, but the third smear showed a significant amount of pus and the patient admitted having had further intercourse with the 
same partner. He was given another course of streptomycin and sulphadimidine and a subsequent smear was again almost devoid of pus. Candida was not visible on the smear but was grown on the Sabouraud culture. The amphotericin B instillation was therefore repeated, but the patient complained of considerable urethral pain after treatment. The instillation was repeated the following day using a solution of half the previous strength (viz. $12.5 \mathrm{mg}$. of amphotericin B) and this caused no discomfort.

Six further smears and cultures were taken from the patient's urethra over the next 3 months and no evidence of Candida was discovered. It is perhaps of interest that the patient had by this time broken his association with his girl friend. He had consistently refused to allow her to be examined.

\section{Discussion}

Castellani and Chalmers (1919) are credited with first describing urethritis of mycotic origin. They classified three types of urethral discharge: white discharge with Candida and less commonly Nocardia; red discharge with Candida, Cryptococcus, and Saccharomyces; black discharge with Cladosporium, Aspergillus, and Penicillium. The colours were said to be due to pigment producing yeasts and bacilli. This clinicopathological classification was later reaffirmed by the same author (Castellani, 1962). A venereal origin of most cases was assumed, but in another of his patients (Castellani, 1925), a young Serbian officer 'of good moral character' who attended with a purulent urethral discharge from which Candida was isolated, the urethritis was considered to be non-venereal. The patient did have a fiancée, however, about whom details were not given.

Pisacane and Coppolino (1938) described five cases of mycotic urethritis seen in Messina. All these patients had recently arrived from Africa and had a urethral discharge of presumed venereal origin, with incubation periods of from 15 days to 3 months. Smears revealed epithelial cells and scanty pus cells. Three of the cultures yielded Cryptococcus ruber, one Penicillium candidum, and one Candida tropicalis.

Coutts (1948) described two cases of candidal urethritis in males. Both were stated to be 'conjugal infections' but we are not told definitely that their wives had vaginal candidosis.

A veritable epidemic of fungal infections of the urethra apparently occurred at the Manchester Royal clinic in 1953. Auckland and Preston (1954) described 36 male cases in which fungi were isolated from the urethra, prostate, or urine. The fungi included $C$. albicans, Penicillium, Aspergillus, and C. krusei, but the proportion of Candida infections is not given. Most cases had a slight urethral discharge with fungal elements, scanty pus cells, and many epithelial cells in the smears. The authors suggested that the widespread use of 'broad spectrum' antibiotics might have been responsible for the high incidence of fungal infections. However, nineteen of the 36 men denied having received antibiotics at any time. The proportion of uncircumcised males or the presence or absence of extragenital mycotic lesions or diabetes was not stated.

Fowler (1958) reported a case of urethral candidosis in a diabetic married man aged 54 years. The discharge was slight, few pus cells and abundant epithelial cells being present. $C$. albicans was identified in smears and cultures. Urethroscopy revealed a white membrane covering the urethra. His wife had no vaginitis but spores were visible in her vaginal smear.

Catterall (1966) collected twelve cases of urethral candidosis in males. Eight of these patients had recently received antibiotic therapy and in all cases the symptoms were mild. $C$. albicans was isolated from the vaginas of the sexual partners in ten cases. The number of uncircumcised men in the series is not mentioned, but balanitis was present in three. Treatment was with urethral irrigations with dequalinium chloride or nystatin.

The increased reporting of Candida infections, especially of the genito-urinary tract, since the accelerated use of antibiotics in the late 1940s and early 1950s has been noted by many observers. (Lancet, $1951,1952)$. Haley (1965), studying the frequency of C. albicans in 'clean catch' urine specimens, concluded that antibiotics favoured the induction of candidosis by suppression of enterobacilli. Candida is known to be inhibited by the presence of $E$. coli and to a lesser extent by other Gram-negative bacilli such as Proteus, paracolon, and Klebsiella aerobacter (Paine, 1958). Siboulet (1963) reported several cases of candidal urethritis in some of which antibiotics had previously been given for undiagnosed urethral discharge.

The case reported here was treated with tetracycline shortly before urethral Candida was found for the first time. It is of interest that large amounts of pus were never noted in the presence of the fungus, suggesting that the fungus may have been inhibited by pyogenic agents, known or unknown. Autoinoculation could be ruled out because the patient was circumcised and foci of infection in the prostate and bladder were also excluded. The efficacy of amphotericin B instillation seemed undoubted but the fact that the patient had abandoned his liaison with his sexual contact no doubt contributed to his cure.

\section{Summary}

A case of urethral candidosis and its treatment with amphotericin B instillations in a man aged 32 years is described. The literature on the subject of candidal infections of the urethra is briefly discussed. 


\section{References}

Auckland, G., and Preston, W. J. (1954). Brit. F. vener. Dis., 30, 81.

Castellani, A. (1925). F. trop. Med. Hyg., 28, 250.

- (1962). Ann. N.Y. Acad. Sci., 93, 147. - and Chalmers, A. J. (1919). 'A Manual of Tropical Medicine', 3rd ed., p. 1943. Baillière, Tindall and Cox, London.

Catterall, R. D. (1966). In H. I. Winner and R. Hurley's 'Symposium on Candida Infections'. Livingstone, Edingburgh.

CoutTs, W. E. (1948). Brit. f. vener. Dis., 24, 109.

FOWLER, W. (1958). Ibid., 34, 166.

Haley, L. D. (1965). Sabouraudia, 4, 98.

HARKNESS, A. H. (1950). 'Non-Gonococcal Urethritis', pp. 248-254. Livingstone, Edinburgh.

Lancet (1951). Annotation, 2, 532.

-.- (1952). Annotation, 1, 352.
Paine, T. F. (1958). Antibiot. and Chemother., 8, 273.

Pisacane, C., and Coppolino, A. (1938). f. trop. Med. Hyg., 41, 332.

RohATINER, J. J. (1967). Med. Gynaec. Sociol., 2, no. 4, p. 2.

Siboulet, A. (1963). Presse méd., 71, 2779.

Candidose urétrale masculine traitée par des instillations intra-urétrales d'amphotéricine $B$

SOMMAIRE

Description d'un cas de candidose urétrale et de son traitement par des instillations intra-urétrales d'amphotéricine B chez un homme des trente six ans. La littérature concernant l'infection de l'urètre à candida est brièvement discutée. 